\title{
PREDICTION OF BEACH CHANGES AROUND ARTIFICIAL REEF USING BG MODEL
}

\author{
Hiroaki Fujiwara ${ }^{1}$, Takaaki Uda ${ }^{2}$, Toshiaki Onishi' ${ }^{1}$, Shiho Miyahara ${ }^{3}$ and Masumi Serizawa ${ }^{3}$
}

On the Kaike coast, one of the twelve detached breakwaters was converted into an artificial reef. After the conversion, the tombolo behind the structure was reduced in size because of the generation of shoreward currents on the artificial reef, and severe scouring occurred at the opening between the artificial reef and the existing detached breakwater owing to the development of rip currents. To investigate this, the BG model (a 3-D model for predicting beach changes based on Bagnold's concept) proposed by Serizawa and Uda was improved to include the effect of not only waves but also strong nearshore currents. Also, the increase in the depth of closure due to currents was considered in the model. The predicted and measured beach changes around an artificial reef were in good agreement.

Keywords: artificial reef; detached breakwater; beach changes; rip currents; BG model; Kaike coast

\section{INTRODUCTION}

The Kaike coast with a $20 \mathrm{~km}$ stretch is the marginal coast along the Yumigahama Peninsula in Miho Bay in Tottori Prefecture facing the Sea of Japan (Fig. 1). This peninsula has developed as a tombolo by the deposition of sand from the Hino River owing to the wave-sheltering effect of the Shimane Peninsula. After World War II, beach erosion along the Kaike coast occurred owing to the decrease in sand supply from the Hino River. A famous spa of Kaike is located near the shoreline immediately west of the Hino River, and therefore, the beach around this spa was protected by groins in the 1960s. Then, 12 detached breakwaters were constructed between 1971 and 1982 as a measure against beach erosion, and tombolo was formed behind each of the detached breakwaters.

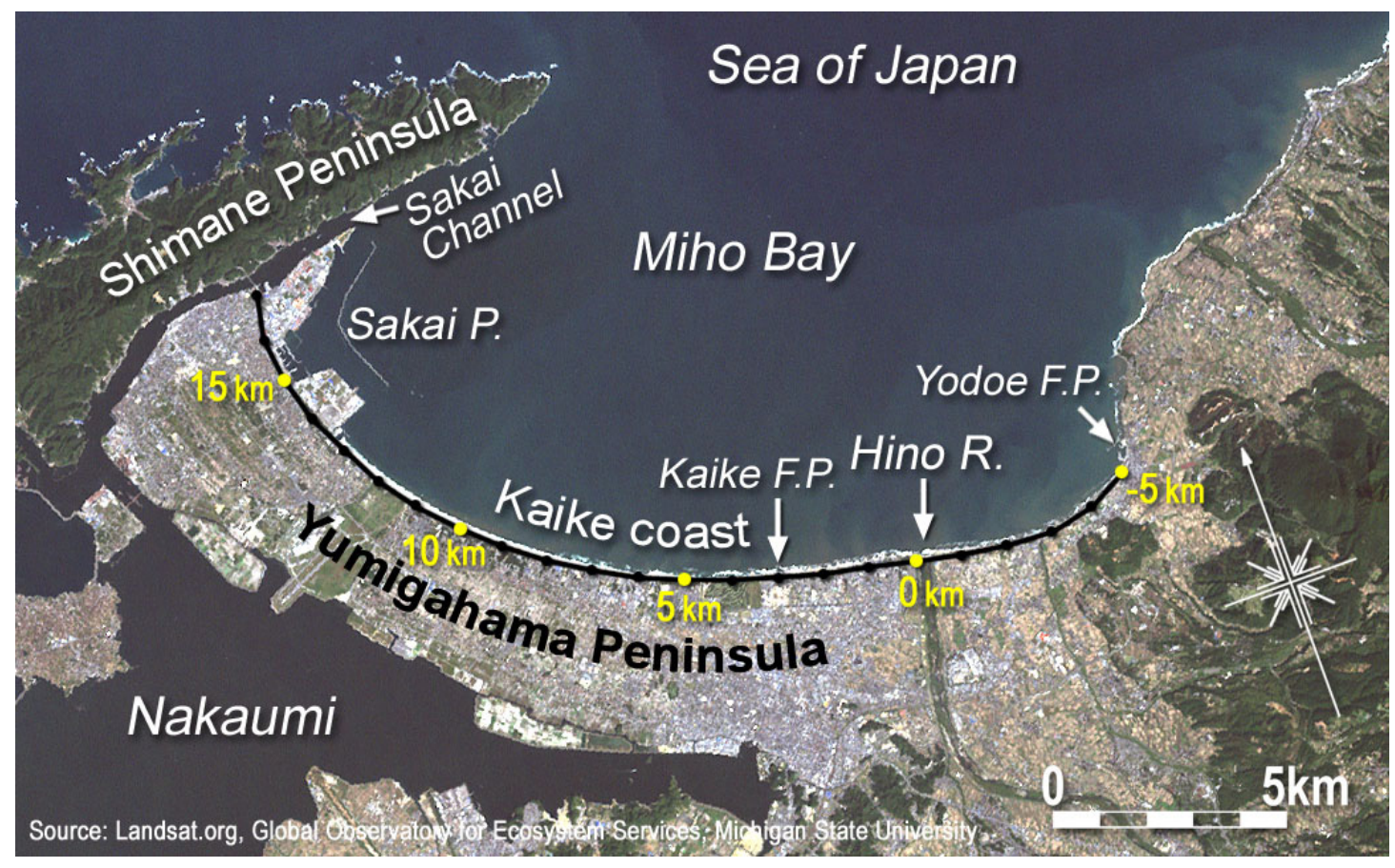

Figure 1. Location of Kaike coast facing the Sea of Japan.

\footnotetext{
${ }^{1}$ Hino Office of River, Chugoku Regional Development Bureau, Ministry of Land, Infrastructure, Transport and Tourism, Kohouchi 678, Yonago, Tottori 689-3537, Japan

2 Public Works Research Center, 1-6-4 Taito, Taito, Tokyo 110-0016, Japan

${ }^{3}$ Coastal Engineering Laboratory Co., Ltd., 1-22-301 Wakaba, Shinjuku, Tokyo 160-0011, Japan
} 
Figure 2 shows the aerial photograph of the detached breakwaters of the Kaike coast taken in 2003, showing the formation of tombolos behind the detached breakwaters. Here, the number of the breakwater in Fig. 2 shows the order of the construction and hereafter, each breakwater is called by this number. The Hino River, which is the major source of sand supply, flows into the coast at the east end. Although these detached breakwaters and tombolos have been stable until 2003, concrete armor units placed immediately offshore of the shoreline near the Kaike Spa spoiled the scenic beauty of the area as a recreational beach and extremely narrowed the swimming space, as typically shown in Fig. 3, and the foreshore slope was excessively steepened at the opening of the detached breakwaters. Therefore, an artificial reef with crests was constructed in place of the No. 3 detached breakwater in 2005. After the construction, the tombolo was reduced in size because of the generation of shoreward currents on the artificial reef, and severe scouring occurred at the opening between the artificial reef and the existing detached breakwaters owing to the development of rip currents.

In this study, we improved the BG model proposed by Serizawa and Uda (2011) by incorporating the effect of not only waves but also strong nearshore currents into the model, as well as increase in the depth of closure due to the strong currents. Then, we applied the model to the Kaike coast.

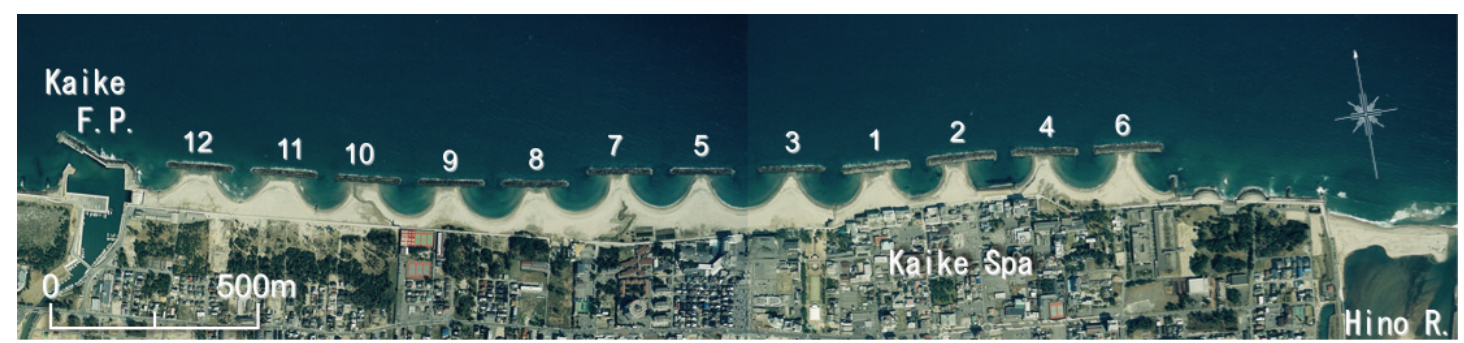

Figure 2. Aerial photograph of beaches around twelve detached breakwaters of Kaike coast taken in 2003.

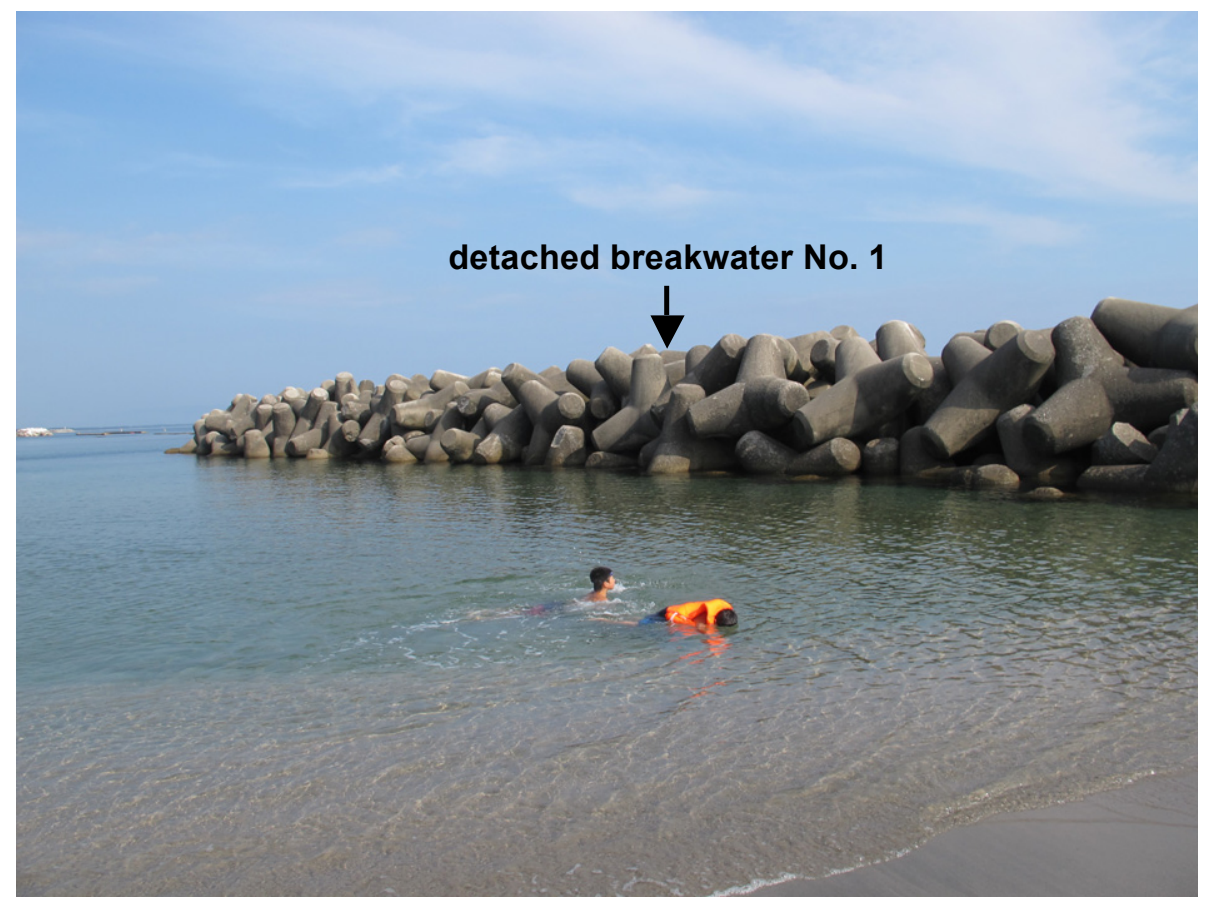

Figure 3. Spoiled scenic beauty and extremely narrowed swimming space. 


\section{BEACH CHANGES AFTER CONSTRUCTION OF ARTIFICIAL REEF}

Figure 4 shows the bathymetry in July 2002 before the conversion of the No. 3 detached breakwater into the artificial reef. In 2002, a tombolo was formed behind the No. 1, 3 and 5 detached breakwaters owing to their wave-sheltering effect, and semicircular contours were formed in the opening between the detached breakwaters. In addition, the foreshore slope was as steep as 1/7 at the central part of the opening. One of the objectives of converting the detached breakwater into an artificial reef was to create a gentle slope near the shoreline that is convenient for recreational use because of the steep slope near the shoreline. The artificial reef had a crown height of $0.5 \mathrm{~m}$ below the mean sea level (M.S.L.) and a width of $40 \mathrm{~m}$, as well as two rows of crests that enhance the wave attenuation effect, as shown in Fig. 5. Here, the H.W.L. and L.W.L. of this coast are +0.36 and $-0.56 \mathrm{~m}$ above the M.S.L.

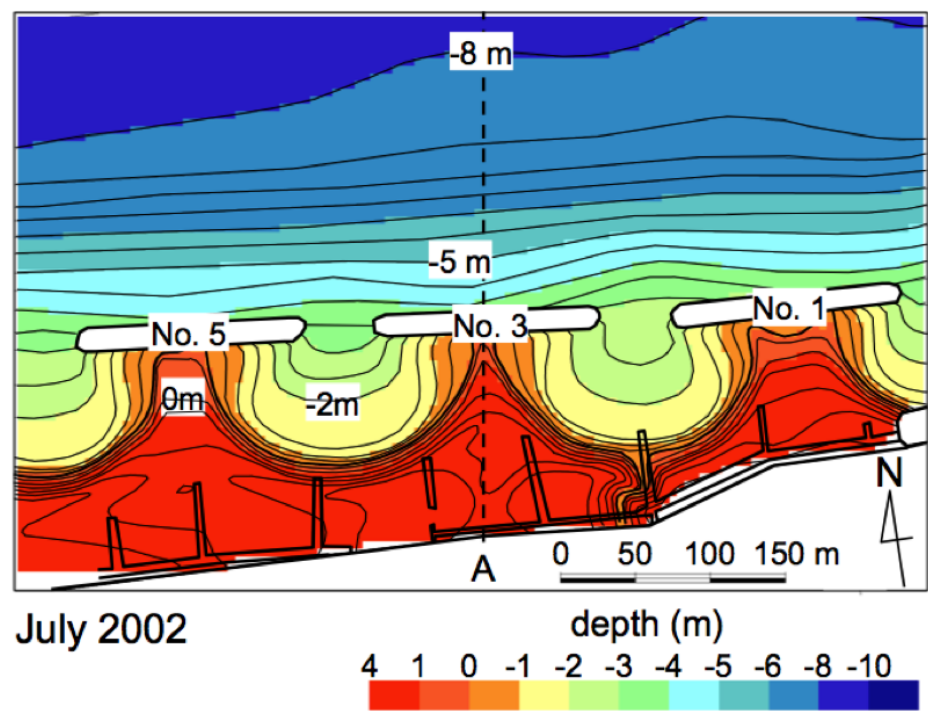

Figure 4. Bathymetry measured in July 2002 before conversion of detached breakwater into artificial reef.

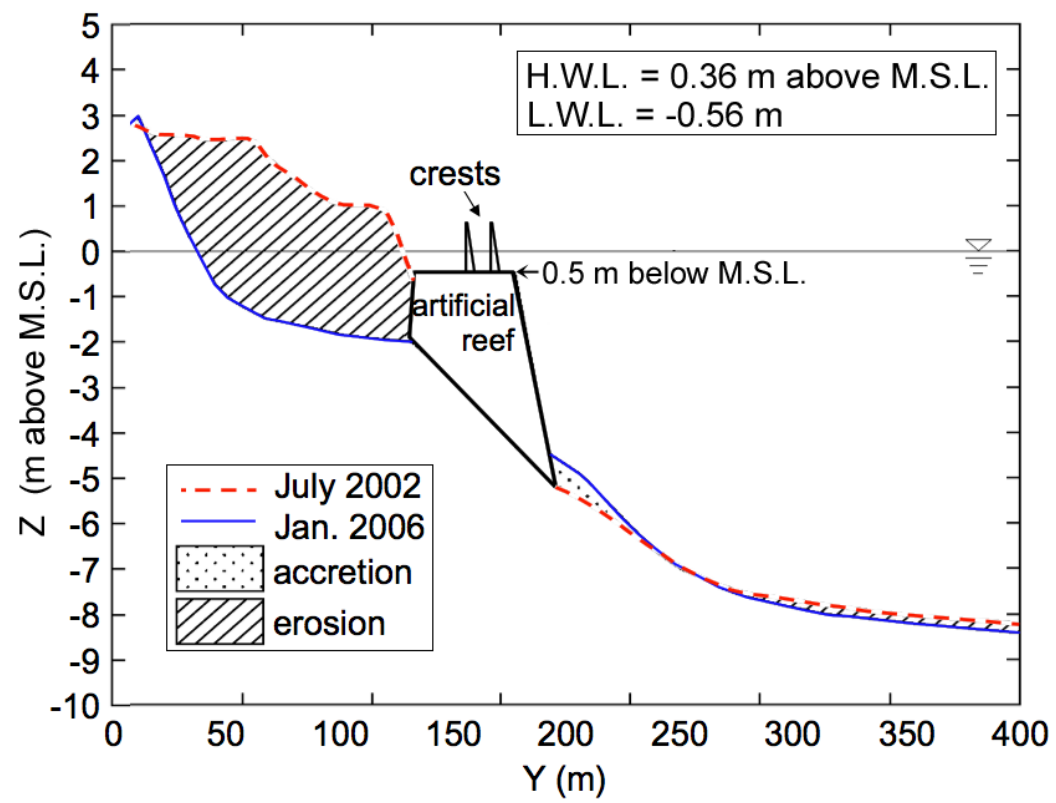

Figure 5. Cross section of artificial reef with crests. 
After the construction of the artificial reef, storm waves associated with a low pressure hit the reef in December 2005. Figure 6 shows the changes in significant wave height and wave period measured at a depth of $8 \mathrm{~m}$ offshore of the artificial reef. The maximum significant wave height was $4.5 \mathrm{~m}$ and the wave period was $12 \mathrm{~s}$, with a 30-hr duration of storm waves higher than $3 \mathrm{~m}$. As a result, the bathymetry around the artificial reef was deformed in January 2006, as shown in Fig. 7, and the longitudinal profile changed, as shown in Fig. 5. The tombolo behind the detached breakwater disappeared, resulting in the formation of a flat shallow seabed of $2 \mathrm{~m}$ depth.

Figure 8 shows the bathymetric changes around the artificial reef before and after the construction of the artificial reef. Not only did the tombolo formed behind the detached breakwater disappear but also a deep scouring hole with a maximum depth of $7 \mathrm{~m}$ was formed at the west end of the artificial reef (Fig. 7). The local scouring at both ends of the artificial reef showed asymmetry, and the scouring hole at the west opening was larger than that at the east opening. Thus, it is considered that predominant waves were incident from the east, producing westward longshore currents. Furthermore, the tombolo behind the No. 5 detached breakwater west of the artificial reef was eroded and the shoreline retreated, implying the development of westward longshore currents passing through the lee of the No. 5 detached breakwater, which in turn eroded the beach in the lee of the No. 5 detached breakwater.

Finally, it was found that converting the detached breakwater into an artificial reef caused the disappearance of the tombolo, the local scouring at the opening and the reduction in the size of the tombolo behind the nearby detached breakwater.
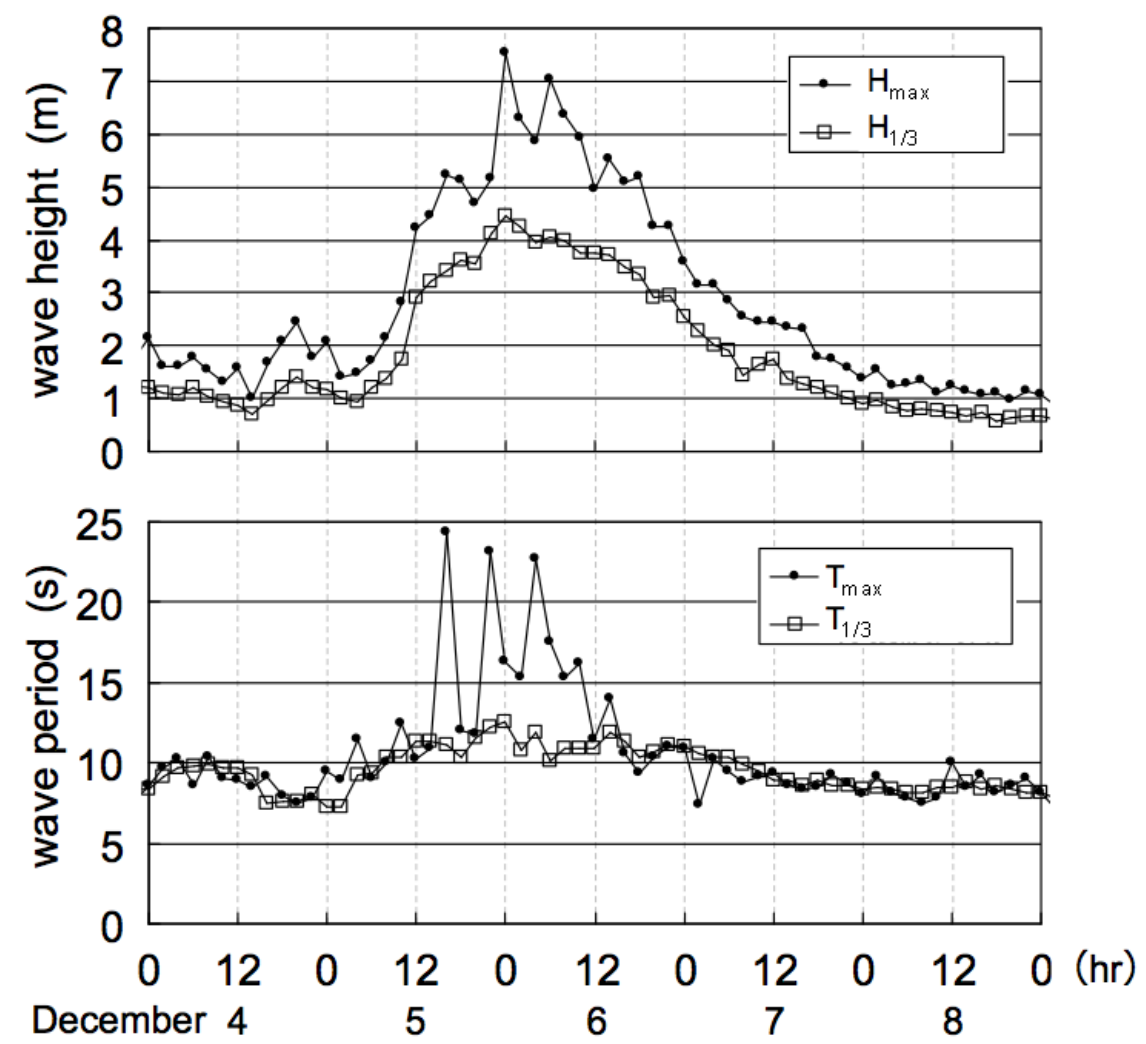

Figure 6. Significant wave height and wave period associated with low pressure occurred in December 2005. 


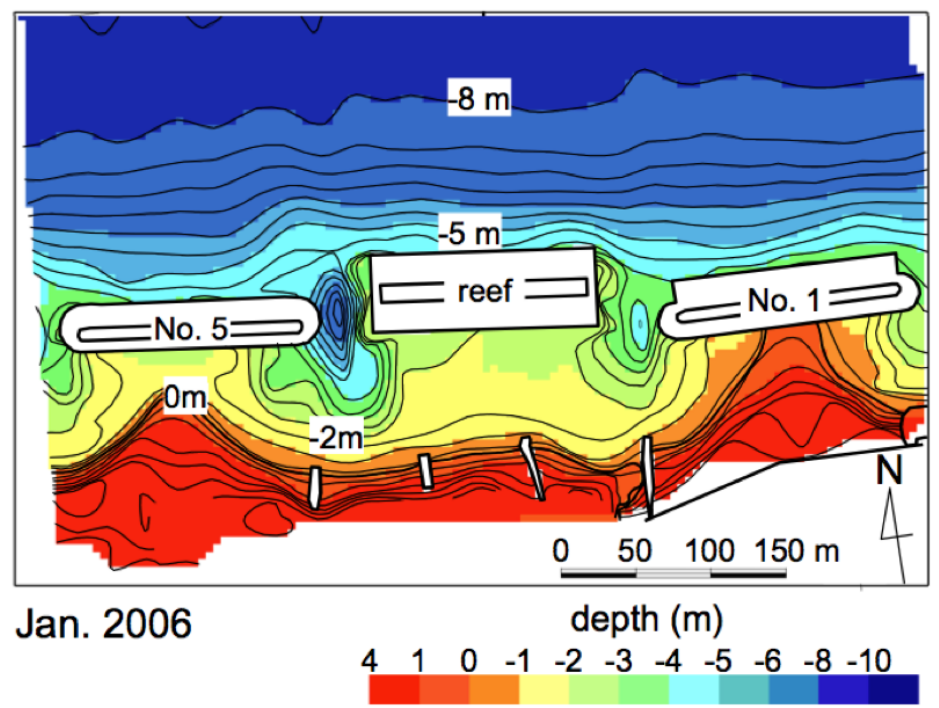

Figure 7. Bathymetry after storm waves measured in January 2006.

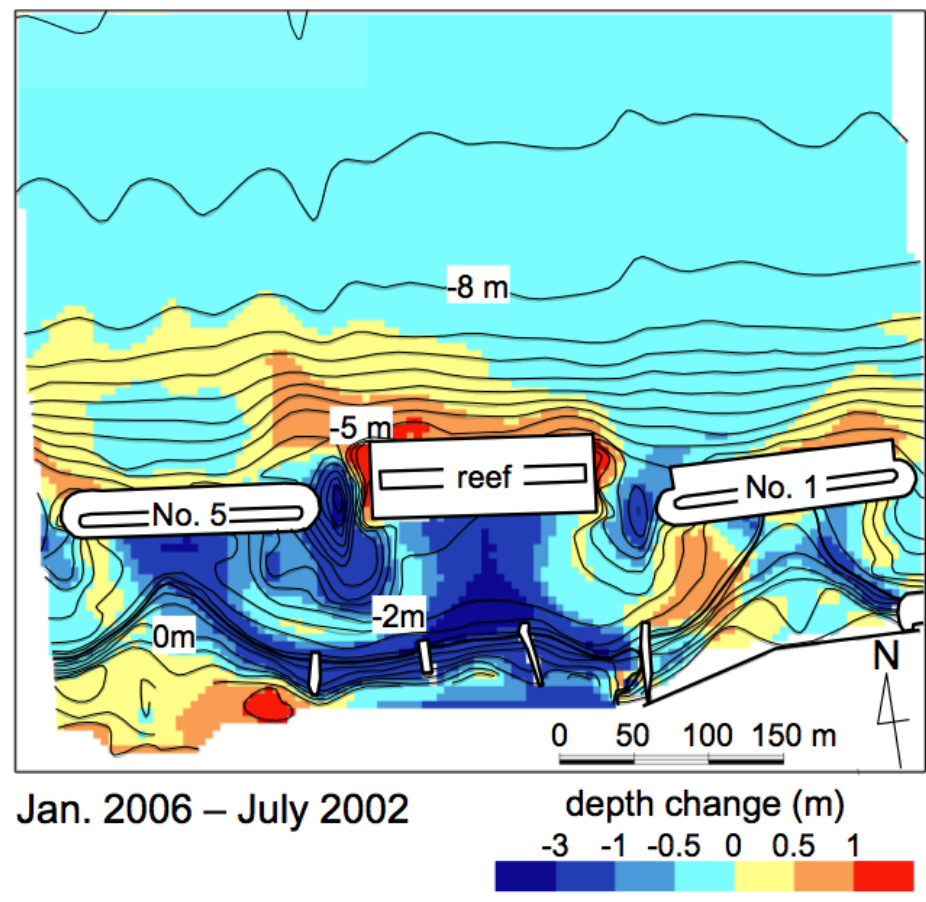

Figure 8. Bathymetric changes from July 2002 to January 2006.

\section{PREDICTIVE MODEL}

The BG model proposed by Serizawa and Uda (2011), in which Bagnold's concept (Bagnold, 1963 ) is used, was improved, taking both the wave field and the current velocity at a local point into account. The fundamental equations of the model are given by Eqs. (1) - (6) on the Cartesian coordinates $(x, y)$, assuming that the sand transport flux $\vec{q}=\left(q_{x}, q_{y}\right)$ is a linear sum of the component due to waves, $\overrightarrow{q_{w}}=\left(q_{w x}, q_{w y}\right)$, and that due to currents, $\overrightarrow{q_{c}}=\left(q_{c x}, q_{c y}\right)$.

$$
\vec{q}=\overrightarrow{q_{w}}+\overrightarrow{q_{c}} \quad\left(-h_{c} \leq Z \leq h_{R}\right)
$$




$$
\begin{gathered}
\overrightarrow{q_{w}}=C_{0} \frac{P_{w}}{\tan \beta_{c}}\left(\tan \beta_{c} \overrightarrow{e_{w}}-b_{1} \overrightarrow{\nabla Z}\right) \\
P_{w}=K_{w} \cdot \rho u_{m}{ }^{3} \\
\overrightarrow{q_{c}}=C_{0} \frac{P_{c}}{\tan \phi}\left(\tan \phi \overrightarrow{e_{c}}-b_{2} \overrightarrow{\nabla Z}\right) \\
P_{c}=K_{c} \cdot \rho u_{m}{ }^{2} V \\
u_{m}=H / 2 \sqrt{g / h}
\end{gathered}
$$

Here, $\vec{q}$ is the total sand transport, $\overrightarrow{q_{w}}$ is the sand transport due to waves, $\overrightarrow{q_{c}}$ is the sand transport due to currents, $\overrightarrow{\nabla Z}=(\partial Z / \partial x, \partial Z / \partial y)$ is the slope vector, $\tan \beta=|\overrightarrow{\nabla Z}|$ is the seabed slope, $Z(x, y, t)$ is the seabed elevation, $\tan \beta_{c}$ is the equilibrium slope, $\overrightarrow{e_{w}}$ is the unit vector of the wave direction, $\overrightarrow{e_{c}}$ is the unit vector of the current direction, $u_{m}$ is the amplitude of the seabed velocity due to the orbital motion of waves, $H$ is the wave height, $h$ is the water depth, $b_{1}=\left|\cos \alpha_{1}\right|, \alpha_{1}$ is the angle between the wave direction and the direction normal to the contour lines, $V$ is the velocity of currents, $K_{w}$ and $K_{c}$ are the coefficients of sand transport due to waves and currents, respectively, $b_{2}=\left|\cos \alpha_{2}\right|, \alpha_{2}$ is the angle between the direction of currents and the direction normal to the contour lines, $\tan \phi$ is the slope of the angle of repose of sand, and $C_{0}$ is the coefficient transforming the immersed weight expression into the volumetric expression $\left(C_{0}=1 /\left\{\left(\rho_{s}-\rho\right) g(1-p)\right\}\right.$, where $\rho$ is the density of seawater, $\rho_{s}$ is the specific gravity of sand particles, $p$ is the porosity of sand, and $g$ is the acceleration of gravity). $h_{c}$ is the depth of closure and $h_{R}$ is the berm height.

Here, $b_{2}$ is assumed to be 0 in the calculation. In the calculation of beach changes, the wave field and nearshore currents were calculated first, and then beach changes were predicted. The sand transport equations of Eqs. (2) and (4) were derived on the basis of Bagnold's concept as is the case of Serizawa et al. (2008).

The wave field was calculated using the energy balance equation given by Mase (2001) with the energy dissipation term due to wave breaking (Dally et al., 1984). As the spectrum of the incident waves, the combination of the frequency spectrum of the Bretchnider-Mitsuyasu type and the Mitsuyasu-type directional function was used. The total number of frequency components is $N_{f}=1$, the number of directional subdivisions is $N_{\theta}=8$ and the directional spreading parameter is $S_{\max }=10$.

When an artificial reef is constructed, strong shoreward currents are generated by the forced wave breaking, producing rip currents at the opening between the artificial reef and the existing detached breakwaters. The effects of these currents were not considered in the previous BG model (Serizawa and Uda, 2011), which employed only the wave field without calculating the nearshore currents, although the effect of longshore currents was implicitly considered in the sand transport equation described using the local wave characteristics. In this study, the effect of the nearshore currents induced by forced wave breaking was incorporated into the model by calculating the nearshore currents using the method by Horikawa (1988). To calculate the nearshore currents, the scheme of upwind finite difference was used for the momentum equation along with the lateral diffusion term by Larson and Kraus (1991).

In the calculation of the wave field on land, the imaginary depth was assumed to calculate the beach changes between the berm height and the shoreline. The imaginary depth $h^{\prime}$ was considered as Eq. (7) between the minimum depth $h_{0}$ and the berm height $h_{R}$.

$$
h^{\prime}=\left(\frac{h_{R}-Z}{h_{R}+h_{0}}\right)^{\mathrm{r}} h_{0} \quad(\mathrm{r}=1) \quad\left(-h_{0} \leq Z \leq h_{R}\right)
$$

Here, $h_{0}$ was assumed to be $3 \mathrm{~m}$, the same as the berm height $h_{R}$. The wave energy was set to be 0 in the area with an elevation higher than the berm height. Although the depth of closure $h_{c}$ was assumed to be $2.5 H$, where $H$ is the wave height at a local point, the increment due to the effect of the strong rip currents was evaluated as

$$
h_{c}^{\prime}=\left\{1+a\left(V / u_{m}\right)\right\} h_{c}
$$

Here, $V$ is the velocity of nearshore currents, and $a$ is a coefficient of 0.5 . 


\section{CALCULATION CONDITIONS}

On the basis of the bathymetric survey data in 2009, a rectangular calculation area of $1800 \mathrm{~m}$ length and $700 \mathrm{~m}$ width including the No. 3 detached breakwater, which was later converted into an artificial reef, was selected. As the initial bathymetry, the assumption that tombolos behind the detached breakwaters have sufficiently developed was set, as shown in Fig. 9(a). The offshore slope was set to be $1 / 30$ in the depth zone between -5 and $-8 \mathrm{~m}$, and 1/100 in the zone deeper than $-8 \mathrm{~m}$, the same as the field conditions. Under these conditions, the storm wave conditions on the Kaike coast with a significant height $H_{i}=3 \mathrm{~m}$ and a period of $8 \mathrm{~s}$ were assumed to be incident from the right with an angle of $\theta_{i}=10^{\circ}$. The re-calculation of the wave field and nearshore currents was carried out at every 5000 steps of the calculation of the topographic changes. Table 1 shows the calculation conditions. The berm height was set to be $3 \mathrm{~m}$, the equilibrium slope was given as shown in Table 1 depending on the water depth, and the slope of the angle of repose was set to be $1 / 2$. The calculation domain was divided by meshes placed of $20 \mathrm{~m}$ intervals in the longshore and cross-shore directions, and the calculation was carried out up to $40 \mathrm{hr}\left(10^{4}\right.$ steps $)$ at the time interval of $\Delta t=0.004 \mathrm{hr}$.

Table 1. Calculation conditions.

\begin{tabular}{|c|c|}
\hline Calculation model & BG model taking wave and nearshore current fields into account \\
\hline Initial bathymetry & $\begin{array}{l}\text { Bathymetry before conversion of detach breakwater into artificial reef } \\
\text { tombolos are set behind artificial reef } \\
\text { - straight parallel contours with beach slope of } 1 / 30 \text { in offshore zone between }-5 \text { and }-8 \\
\mathrm{~m} \text {, and that of } 1 / 100 \text { in depth zone deeper than }-8 \mathrm{~m}\end{array}$ \\
\hline Wave conditions & $\begin{array}{l}\text { Incident waves: } H_{l}=3 \mathrm{~m}, T=8 \mathrm{~s} \text {, wave direction } \theta_{l}=-10^{\circ} \text { relative to normal to initial } \\
\text { shoreline }\end{array}$ \\
\hline Berm height & $h_{R}=3 \mathrm{~m}$ \\
\hline Depth of closure & $\begin{array}{l}h_{c}=2.5 H(H \text { : wave height }) \\
\text { The increment due to the effect of strong rip currents is evaluated as } \\
h_{c}^{\prime}=\left\{1+a\left(V / u_{m}\right)\right\} h_{c} \text {. } \\
\text { Here, } V \text { : velocity of nearshore currents, } u_{m} \text { : amplitude of seabed velocity due to orbital } \\
\text { motion of waves and } a=0.5 \text {. } \\
\text { The lower and upper limits of } h_{c}^{\prime} \text { are } 3 \text { and } 9 \mathrm{~m} \text {, respectively. }\end{array}$ \\
\hline Equilibrium slope & $\begin{array}{l}\tan \beta_{c}=1 / 10 \text { shallower than }-1 \mathrm{~m} \\
\tan \beta_{c}=1 / 30 \text { between } Z=-1 \text { and }-8 \mathrm{~m} \\
\tan \beta_{c}=1 / 100 \text { deeper than }-8 \mathrm{~m}\end{array}$ \\
\hline Angle of repose slope & $\tan \phi=1 / 2$ \\
\hline $\begin{array}{l}\text { Coefficients of sand } \\
\text { transport }\end{array}$ & $\begin{array}{l}\text { Coefficient of sand transport due to currents } K_{c}=7.5 \times 10^{-4} \\
\text { Coefficient of sand transport due to waves } K_{w}=0.5 K_{c}\end{array}$ \\
\hline Mesh size & $\Delta x=\Delta y=10 \mathrm{~m}$ \\
\hline Time intervals & $\Delta t=0.004 \mathrm{hr}$ \\
\hline Duration of calculation & $10^{4}$ steps \\
\hline Boundary conditions & Shoreward and landward ends $q_{x}=0$, right and left boundaries $d q_{y} / d y=0$ \\
\hline $\begin{array}{l}\text { Calculation of wave } \\
\text { field }\end{array}$ & $\begin{array}{l}\text { Energy balance equation (Mase, 2001) } \\
\text {-Term of wave dissipation due to wave breaking: Dally et al. (1984) model } \\
\text {-Wave spectrum of incident waves: combination of frequency spectrum of Bretchnider- } \\
\text { Mitsuyasu type and Mitsuyasu-type directional function } \\
\text {-Total number of frequency components } N_{F}=1 \text { and number of directional subdivisions } \\
N_{\theta}=8 \\
\text {-Directional spreading parameter } S_{\max }=10 \\
\text { - Coefficient of wave breaking } K=0.17 \text { and } \Gamma=0.5 \\
\text {-Minimum depth } h_{\min }=1 \mathrm{~m} \\
\text { - Imaginary depth between } Z=-h_{0} \text { and berm height } h_{R}: h_{0}=3 \mathrm{~m} \\
\text {-Wave energy }=0 \text {, where } Z \geq h_{R}\end{array}$ \\
\hline $\begin{array}{l}\text { Calculation of } \\
\text { nearshore currents }\end{array}$ & $\begin{array}{l}\cdot \text { Two-dimensional shallow water momentum equation and continuity equation (Horikawa } \\
\text { ed., 1988) } \\
\cdot \text { Friction coefficient } C_{f}=0.01 \\
\text { - Lateral diffusion coefficient } N=0.5 \text { (Larson and Kraus, 1991) } \\
\text {-Minimum water depth } h_{\min }=1 \mathrm{~m}\end{array}$ \\
\hline Other remarks & $\begin{array}{l}\cdot \Gamma=0.55 \text { on crown of artificial reef } \\
\text { - Calculation of wave and nearshore currents: every } 5000 \text { steps of calculation of beach } \\
\text { changes } \\
\text {-Wave transmission coefficient of detached breakwater } K_{t}=0.15\end{array}$ \\
\hline
\end{tabular}




\section{RESULTS}

\section{Beach changes around detached breakwater and artificial reef}

To investigate the difference between the functions of the detached breakwater and artificial reef, beach changes after a 40-hr wave action in the case of the detached breakwater, in which all the detached breakwaters were installed, were first predicted using the bathymetry in Fig. 9(a) as the initial bathymetry. Figures 9(b) and 9(c) show the predicted bathymetry after a 40-hr wave action and the bathymetric changes from the beginning in the case of the detached breakwater, respectively.

In the case of the detached breakwater, the beach was slightly eroded around the detached breakwaters and sand was deposited on the foreshore, beach changes were small and the cuspate forelands behind the detached breakwaters were stable, implying that beach changes around the detached breakwaters could be reproduced by the present model.

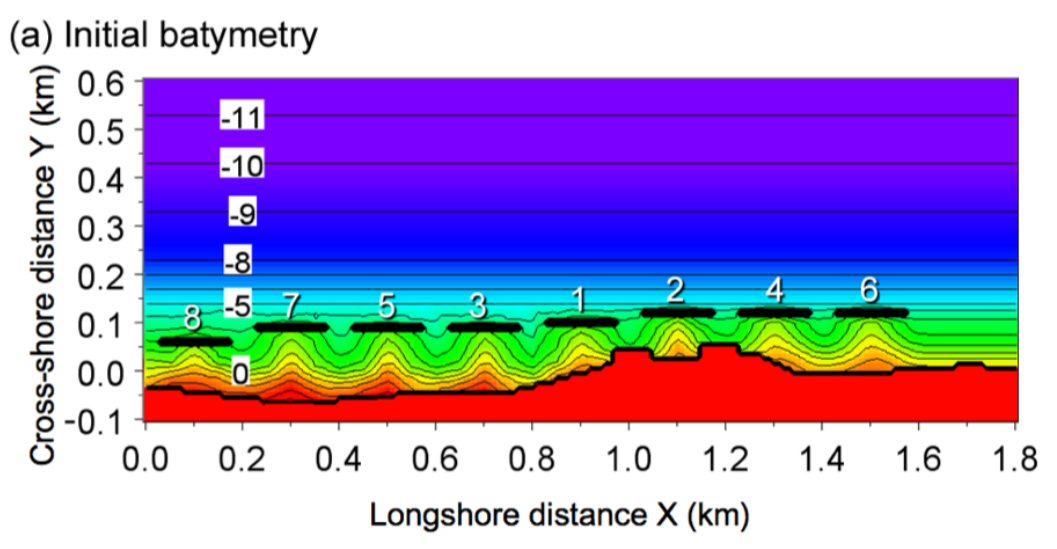

(b) After 40 hours $\left(10^{4}\right.$ steps)
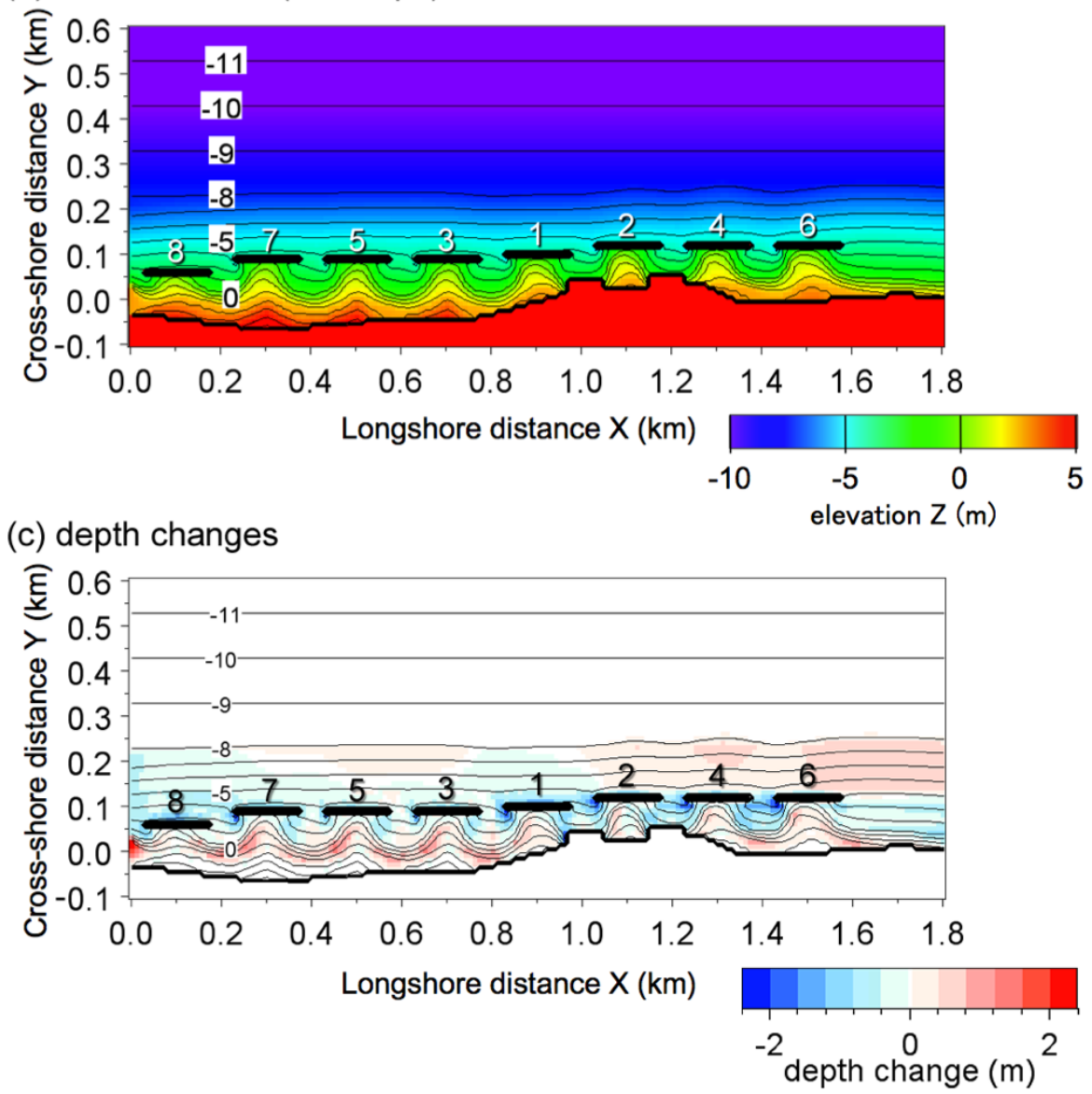

Figure 9. Predicted bathymetries after a 40-hr wave action in case of detached breakwater. 
Figure 10(a) shows the initial bathymetry in the case of the artificial reef which the No. 3 detached breakwater was converted into an artificial reef. After a 40-hr wave action, the tombolo rapidly disappeared and tombolos with a symmetric shape at the initial stage became asymmetric while inclining leftward behind the No. 5 and 7 detached breakwaters west of the artificial reef, as shown in Fig. 10(b). Furthermore, severe local scouring occurred at the west end of the artificial reef. The predicted results were in good agreement with the measured results, as shown in Fig. 7. Furthermore, in the bathymetric changes, as shown in Fig. 10(c), beach was eroded not only shoreward of the artificial reef but also near the area between the artificial reef and the No. 5 detached breakwater located immediately west of the artificial reef.

(a) Initial batymetry

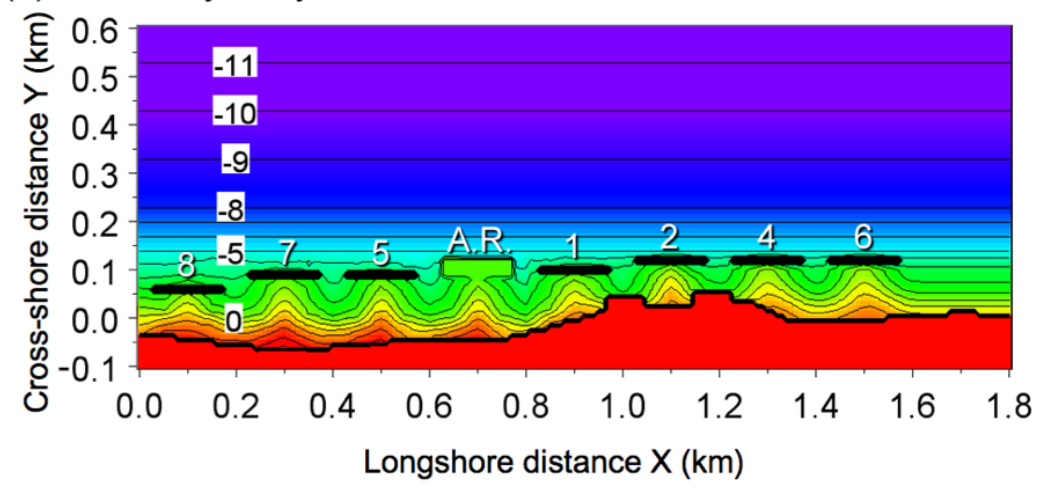

(b) After 40 hours ( $10^{4}$ steps)
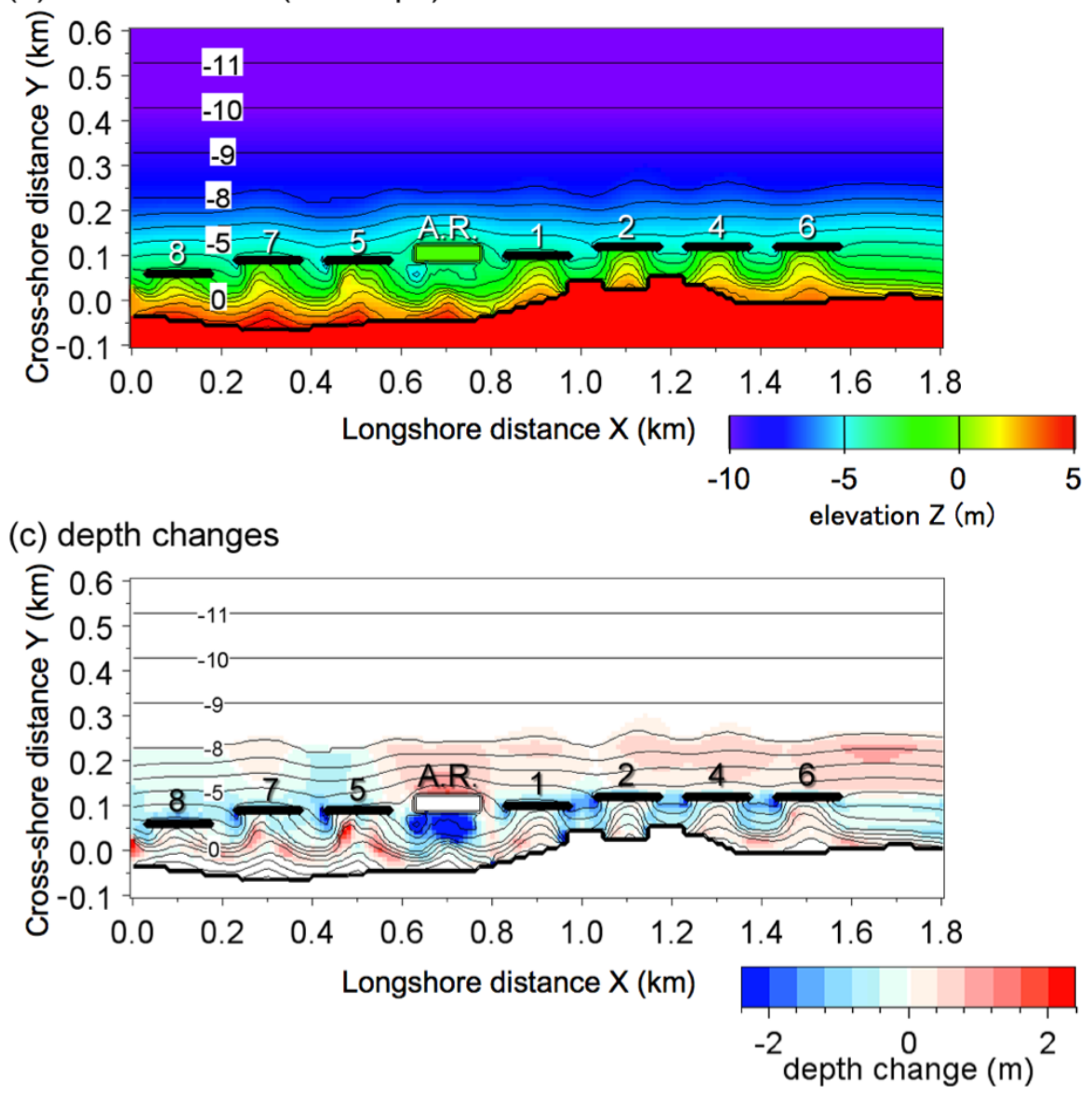

Figure 10. Predicted bathymetries after a $40-\mathrm{hr}$ wave action in case of artificial reef. 
Figure 11 shows the shoreline changes behind the detached breakwaters and artificial reef after a 40-hr wave action. In the case of the detached breakwater, the cuspate forelands behind the detached breakwaters hardly changed, whereas the cuspate foreland behind the artificial reef was rapidly reduced.

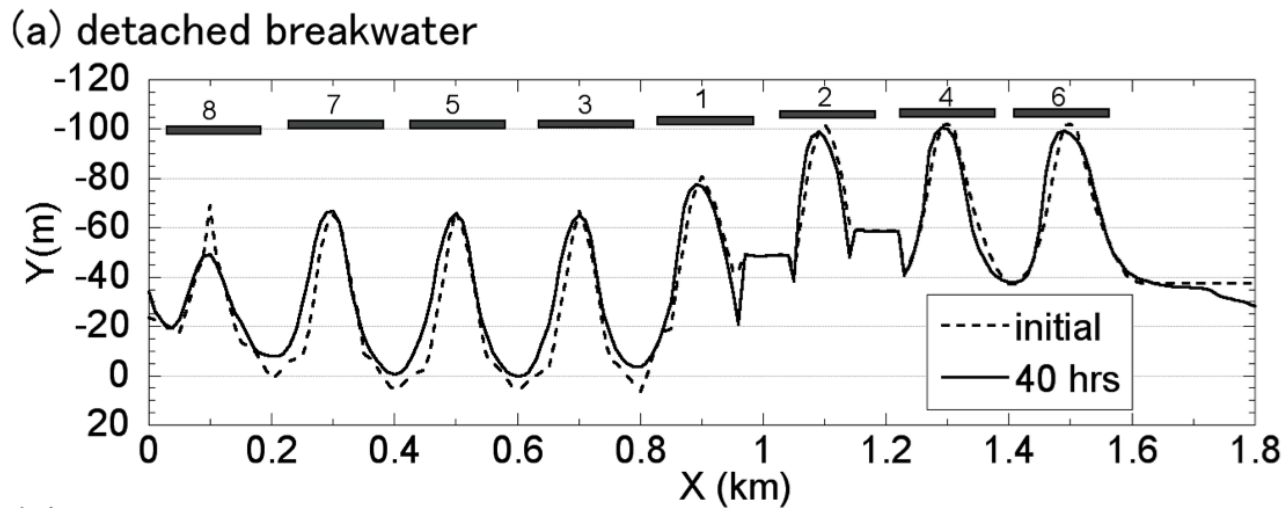

\section{(b) artificial reef}

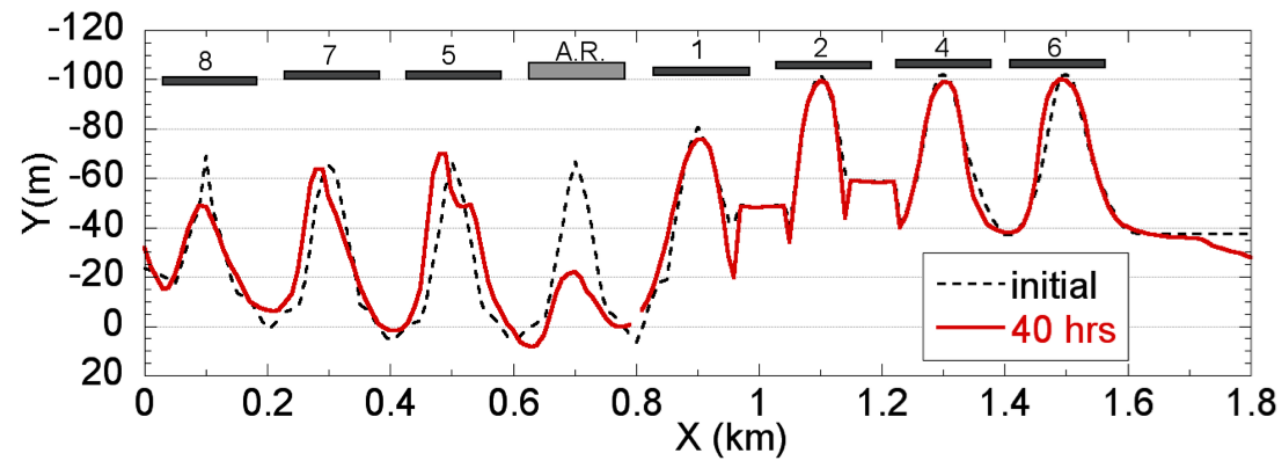

Figure 11. Shoreline changes.

\section{Change in wave field and nearshore currents}

To investigate the difference between the topographic changes behind the detached breakwater and artificial reef, the wave field and distribution of nearshore currents under the oblique wave incidence after a 40-hr wave action were predicted, as shown in Figs. 12 and 13. Although the wave height distributions around the detached breakwaters and artificial reef are similar, as shown in Figs. 12(a) and 12(b), marked changes can be seen in the nearshore currents around the detached breakwaters and the artificial reef. In the case of the detached breakwater, a couple of circulating currents were generated in the lee of the detached breakwaters, as shown in Fig. 13(a), whereas strong shoreward currents were induced on the reef and such currents reduced to rip currents obliquely flowing offshore at the opening between the artificial reef and the existing detached breakwater, as shown in Fig. 13(b).

Because it was difficult for the seawater transported shoreward on the artificial reef to be carried offshore again only by the rip currents, part of the seawater passed through the lee of the detached breakwater and was finally transported away through the openings of the detached breakwaters. The generation of strong shoreward currents on the reef and oblique rip currents in the opening explains the difference between the topographic changes around the detached breakwaters and artificial reef. 
(a) detached breakwater

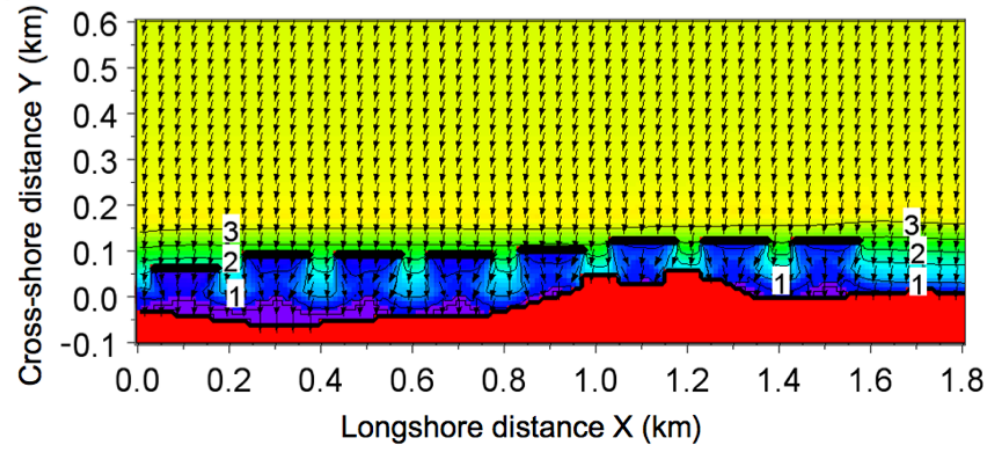

(b) artificial reef

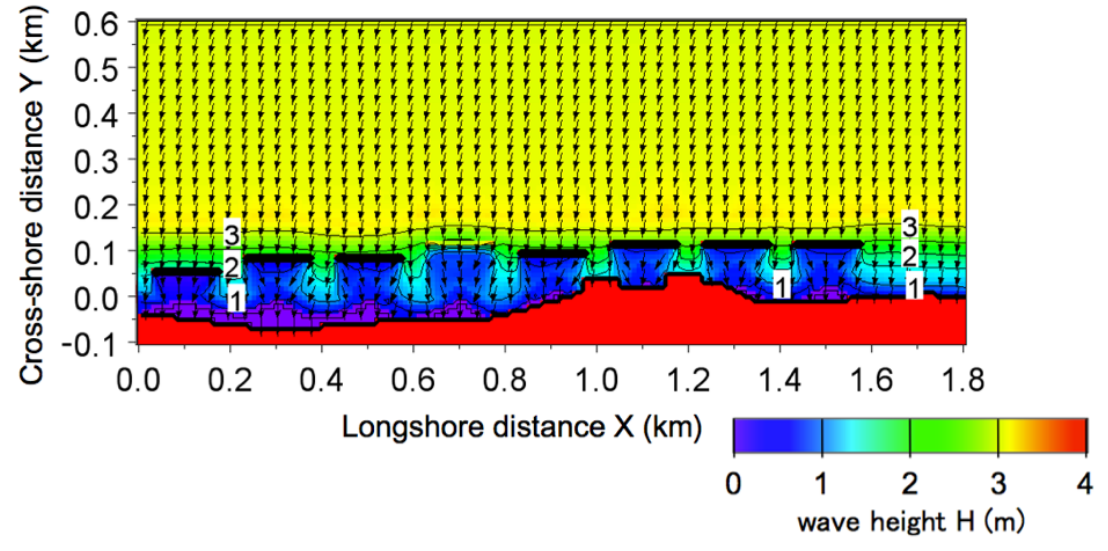

Figure 12. Wave fields around detached breakwater and artificial reef.

(a) detached breakwater

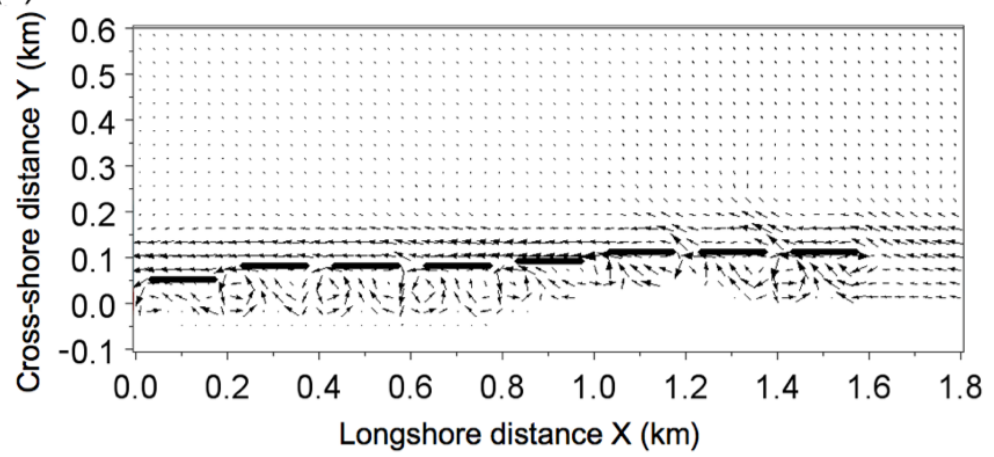

(b) artificial reef

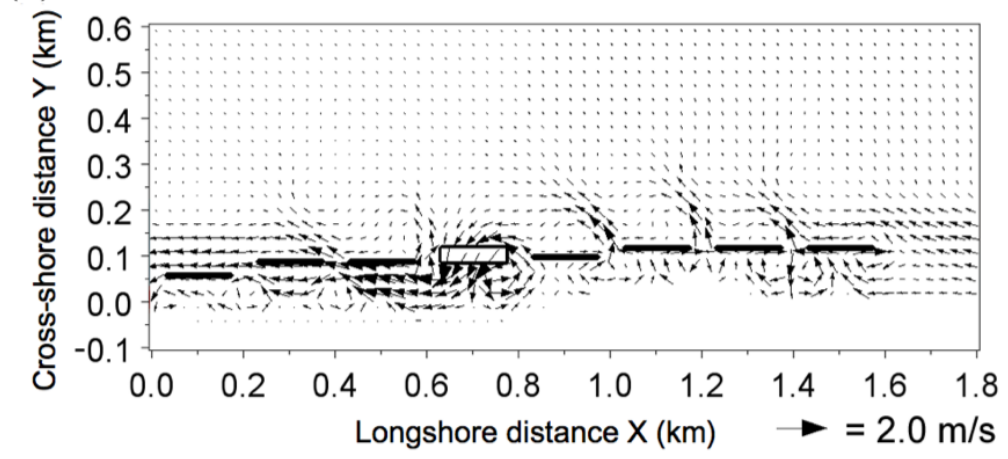

Figure 13. Nearshore currents around detached breakwater and artificial reef. 


\section{CONCLUSIONS}

1. On the Kaike coast, one of the detached breakwaters was converted into an artificial reef. After the conversion, storm wave conditions with a significant wave height of more than $3 \mathrm{~m}$ continued for $30 \mathrm{hr}$ in December 2005. Not only the tombolo behind the artificial reef but also stable tombolos that formed behind the detached breakwaters disappeared, and at the west end of the artificial reef, a local scouring hole with a maximum depth of $7 \mathrm{~m}$ was formed.

2. The effect of the sand transport flux due to strong shoreward currents induced by wave breaking on the reef was explicitly included in the fundamental equations of the BG model.

3. Regarding the local scouring in the opening between the artificial reef and the existing detached breakwaters, rip currents at the opening play an important role. As the effect of rip currents, the increase in the depth of closure due to currents was evaluated, increasing the accuracy of the prediction.

4. Given the same wave conditions as those on the Kaike coast, the calculation of the beach changes around the detached breakwaters and the artificial reef was carried out and the beach changes were successfully predicted using this improved model. The predicted and measured beach changes were in good agreement.

5. Regarding the beach changes around the artificial reef, shoreward currents on the reef and resulted rip currents in the opening play an important role. In addition, the artificial reef is less effective compared with detached breakwater in sand deposition effect.

\section{REFERENCES}

Bagnold, R. A. 1963. Mechanics of marine sedimentation, in The Sea, Hill, M. N. (ed.), Vol. 3, Wiley, New York, 507-528.

Dally, W. R., R. G. Dean, and R. A. Dalrymple.1984. A model for breaker decay on beaches, Proc. 19th ICCE, 82-97.

Horikawa, K. ed. 1988. Nearshore Dynamics and Coastal Processes, University of Tokyo Press, Tokyo, $522 \mathrm{pp}$.

Larson, M., and N. C. Kraus. 1991. Numerical model of longshore current for bar and trough beaches, $J$. Waterway Port Coastal and Ocean Engineering, ASCE, Vol. 117, No. 4, 326-347.

Mase, H. 2001. Multidirectional random wave transformation model based on energy balance equation, Coastal Eng. J., JSCE, Vol. 43, No. 4, 317-337.

Serizawa, M., T. Uda, T. San-nami, K. Furuike, and T. Ishikawa. 2008. Model for predicting formation of dynamically stable ebb tidal delta off tidal inlet, Proc. 31st ICCE, 2291-2302.

Serizawa, M., and T. Uda. 2011. Prediction of formation of sand spit on coast with sudden change using improved BG model, Coastal Sediments ’11, 1907-1919. 